Island Studies Journal, Vol. 11, No. 2, 2016, pp. 619-636

\title{
The research management profession within universities in small island states
}

\author{
Christian Bonnici \\ University of Malta, Malta \\ christian.bonnici@um.edu.mt
}

and

Vincent Cassar

University of Malta, Malta

vincent.cassar@um.edu.mt

\begin{abstract}
The past fifty years have witnessed a widespread increase in the study of small states, including island studies; and the rise of the research management profession and its associated literature. Within a small island state context, the profession cannot be taken for granted, owing to smallness and other inherent characteristics of small island states. These characteristics may potentially re-shape the profession in a unique fashion and may influence the manner in which the roles of university research managers and administrators evolve in a small island state. So far, studies investigating the profession in the context of islands and small states have been lacking. This paper aims to instigate a discussion that hopefully inspires further studies about how the research manager's role and profession may be re-shaped within small island states.
\end{abstract}

Keywords: careers, Iceland, island studies, professions, research management profession, research managers and administrators, Singapore, small island states, smallness, universities

(C) 2016 - Institute of Island Studies, University of Prince Edward Island, Canada

\section{Introduction}

The past fifty years have witnessed a widespread increase in the study of islands and small states; as well as the rise of the research management profession and associated literature. The study of islands is also known as nissology, as proposed by McCall (1994, p. 4) to refer to "the scientific study of islands in their own terms". Although not all islands are small, nissology is quite rich in studies that focus on small islands, including small island states. Defining what is a 'small island state' has never been easy (e.g., Armstrong \& Read, 2003; Crossley, 2008; Sultana, 2006; Thorhallsson, 2006). In this paper, we understand small island states as those independent and sovereign states that are islands with a resident population that does not exceed 1.5 million inhabitants.

Research management refers to the "duties and responsibilities commensurate with the successful implementation of the research strategy and its daily operational implications, the control and co-ordination of specific research projects, their quality and related tasks of sponsor management" (Bushaway, 2007, p. 42). Although research can take various forms (individual, joint/collaborative, multi-disciplinary), for the purposes of this paper, research management is mostly concerned with the more collaborative form of research that requires 
certain organizational structures and demands a certain level of support when compared to individual personal research.

The rise of the research management profession and that of the dedicated role of Research Managers and Administrators (RMAs) started being captured by interested authors in an ever-increasing body of literature on research management (e.g., Bushaway, 2007; Derrick \& Nickson, 2014; Green \& Langely, 2009; Hansen \& Moreland, 2004; Kirkland, 2005; Schuetzenmeister, 2010). However, the effects of smallness and islandness have stayed off the radar of the profession. This gap in the literature may be attributed to the fact that the development of the research management profession and the study of smallness and islandness occurred much around the same time, such that it was not easy for both concepts to be intertwined when both were still in their infancy. Otherwise, it is also possible that the two concepts were still considered to be unrelated to each other such that any possible association between the two remains to be explored. This lacuna in the literature is not surprising, given that various small island states either lack their own national university or partake in a regional university context; consequently, there is no scope for developing any careers for university RMAs in these countries.

In this paper, we instigate a discussion that brings these two, seemingly unrelated, concepts together. The aim is to assess whether the research management profession can flourish within a small island state university, where scarce resources, especially of human capital, might be a significant bottleneck. We do so by evaluating first, the rationale for the profession within a small island state; and, second, by discussing potential ways in which the roles of university RMAs may be re-shaped by the contextual realities of such states. The paper generally reflects our insights gained from the two bodies of literature: on smallness and on research management. It does not provide empirical data that allows generalizations to the entire population of small island states; but is intended to serve as a platform to provoke a discussion and instigate interest into further empirical research about the twinning of the two phenomena.

We shall first have a brief look at the developments of the two phenomena separately. Then we discuss the rationale for the research management profession in small island states. Subsequently, we examine how the roles of university RMAs may be re-shaped by the idiosyncratic context of small island states. The final section draws some conclusions and encourages further research in the field of university research management in and for small island states.

\section{Developments of the two phenomena}

\section{Islands, islandness and the study of islands}

Today, it is generally recognized that there is "much scope for unpacking what is meant by islandness" (Baldacchino, 2004, p. 272). In spite of the great diversity among islands, "island(ers) have a sufficient commonality to warrant looking at them comparatively, justifying a systematic 'island studies' perspective" (Baldacchino, 2005, p. 247). In view of this recognition, interest in small island studies flourished and led to what Baldacchino (2004, p. 272) proclaimed as the "coming of age of island studies". Subsequently, two key journals that focus on islands and island cultures have been set up: Island Studies Journal (ISJ) in 2006 and Shima: The International Journal on Research into Island Cultures in 2007. In an article published in ISJ's inaugural issue, Hay (2006) argues in favour of a coherent theory of islandness. However, he contends that "[defining] what constitutes an island is not 


\section{The research management profession within universities in small island states}

conclusively settled, and what constitutes a small island is a particularly contested issue" (Hay, 2006, p. 20). This complexity arises because there are many types and varieties of islands. They vary in size (large versus small), development (e.g. urban versus rural), climate (from tropical to Arctic/Antarctic), demography (inhabited by aboriginal people versus inhabited by settler/immigrants), geomorphology (continental versus oceanic) and resource availability (resource-rich versus resource-poor islands).

These contrasts are both obvious and elusive. While requiring a 'jack-of-all-trades' approach to the study of islands (King, 2009) they warrant a "critical, inter- and pluridisciplinary study of islands on their own terms" (Baldacchino, 2007, p. 16). Different factors might impact islands in different ways, such that no one single problem affects all islands in the same manner. Therefore, what can matter in one island or a cluster of islands need not necessarily be applicable to all others. When studying islands, one must be wary of what King (2009) terms as "the danger of exceptionalism", since islands may be regarded as too special and too unique. Exceptionalism risks blinking researchers who may somehow regard their islands as different from any other foci of analysis. This danger can be overcome by conducting horizontal comparative studies between islands and by integrating islands vertically within hierarchies of regional and global relations (King, 2009). On the other hand, islands should not be studied with the pre-conception that they are small-scale models of the wider world. King (2009) suggests a middle way, as islands can be studied with rigour, both for themselves and as places where inter-relationships can be studied in deeper focus.

Besides exceptionalism, the smallness of most islands may also denote insignificance, which may be an additional danger that jeopardizes the importance of any problem studied in island states (King, 2009). This perception may be accentuated since, very often, islands are equated to warm weather, tropical locations, holidays, relaxation and having a nice time, without being a serious enough site for scholarly endeavour (ibid.). However, the range of island studies over time has proven that this perception is incorrect. Islands have both similar and distinctive social, economic and environmental problems that warrant being studied separately (Moncada, Camilleri, Formosa \& Galea, 2009). The study of islands may increase its significance when it is combined with the smallness phenomenon. Newitt (1992, p. 16) argues that, "while not all island states are small, the problem of smallness is given an added dimension in the case of an island".

Insignificance may also be countered by the similarity that small provinces of larger states (or jurisdictions) may bear to small island states. Sultana (2006) contends that such jurisdictions may share the features associated with small scale and therefore expand the scope of studying smallness and islandness to a wider population. This wider view makes any reflections and findings on small islands states more significant. In this paper we incorporate the smallness factor with the islandness dimension to evaluate the extent to which the combination of these two elements impacts the research management profession (within universities) in small island states. A brief overview of the developments in the research management profession follows.

\section{The research management profession}

Over the years, research management has become a profession in its own right (Kirkland, 2005; Shambrook \& Roberts, 2011; Shelley, 2010). Yet, it is still a relatively young and developing profession. Its origins are largely attributed to the late 1940s, with the rapid growth of investment by the US government in military and non-military research and laboratories 
after World War II (WWII). This investment became "the catalyst for the need for research administrators" (Beasley, 2006, p. 11), since professional RMAs were now required to support scientific research. The specialized and dedicated role of RMAs has evolved to relieve researchers from unnecessary administrative tasks and thus allowing them to focus more and better on the essence of their research and its results and implications. As the functions of RMAs became more in demand, particularly within universities and research institutions, the role of the RMA has started taking on a more professional character.

Subsequently, the 1950's and 1960's saw the establishment of professional associations that started to focus on supporting the growth of research management as an emerging profession (Trindade \& Agostinho, 2014). The National Council of University Research Administrators (NCURA), the now inactive National Conference on the Administration of Research (NCAR) and the Society of Research Administrators International (SRAI) developed during this period in the US. The publication of the Journal of Research Administration by SRAI and Research Management Review by NCURA demonstrated the growing professionalization of research management, and "the increasing interest in improving management practices and guidelines based on an increasing, empirical evidence base" (Derrick \& Nickson, 2014, p. 16). In Europe, the expansion of the profession is more recent. The European Association of Research Managers and Administrators (EARMA) was set up in 1995. The UK Association of Research Managers and Administrators (UK ARMA) saw its origins in 2001 and has now achieved professional recognition through the establishment of a Professional Development Framework (PDF) for RMAs. From an academic point of view, a number of under-graduate and post-graduate courses existing today contribute towards more commonly understood curricula for the profession (Katsapis, 2012).

These advances in research management have occurred in response to developments in the research enterprise as an academic and professional entity (Gabriele \& Caines, 2014). Governments, private entities and the general public started acknowledging that research can provide an essential contribution towards the well-being of society in general. While these developments have brought greater investment in research, this investment has remained a function of a country's relative resources available for research (Schuetzenmeister, 2010). This meant that the development of the research management profession was also dependent upon the relative wealth of a nation in terms of resources for research and for the support of that research. It is therefore clear that the genesis of research management is embedded in a developed super power: the US after WWII. At the time, expenditure on research and the support of research were considered as an investment aligned with that country's strategic objectives as well as a catalyst for national economic and social development. These investments can be considered as quite estranged to the characteristics of small island states, particularly due to their inherent limited resources and during a phase of de-colonization that was experienced by several small island states post WWII.

However, as more small island territories secured independence from former colonial powers and became more autonomous in their decisions and the allocation of resources, the justification for studying them on their own and in comparison to other jurisdictions has increased. Within this context, small island states, together with similarly small subnational jurisdictions, can be considered as potential objects of study to determine the manner and extent to which their implicit and inherent size, resource limitations and idiosyncratic characteristics re-shape the research management profession and its existence within such states or jurisdictions. We discuss these aspects in some detail below. 


\section{The research management profession within universities in small island states}

\section{The rationale for the research management profession in small island states}

As noted earlier, the research management profession originated from the concerns of a large sovereign state, the US. In such a large and resourceful country, the rationale for the profession became legitimate and went by largely unquestioned. In contrast, the same cannot be said for small island states. Therefore, before analysing and discussing the way the profession is re-shaped in small island states, one had best first reflect on whether there is room for the profession in the first place in such contexts. We discuss the rationale of the profession in small island states by examining three aspects: first, the scope of the research management profession; second the existence or otherwise of universities and their missions (teaching only, research only, or a combination of teaching and research and the ratio of one to the other); and third the rationale for professional associations of research management.

\section{The scope of the research management profession}

An aspect of research management common to other professions is that it does not happen in a vacuum, but requires a context. However, a major complexity of the research management profession is that the context can span various levels. Research can be managed at the national level and is concerned with the management of national research and innovation (R\&I) systems (Schuetzenmeister, 2010). Research can also be managed at the level of funding agencies and it is usually aimed at translating societal problems into research opportunities (ibid.). On a more micro scale, research can be managed at the level of organizations, universities and other research-oriented entities, or even at a lower level, that of a research group. Research management at each of these levels is not automatic: it depends on the structure and organization of the research ecosystem of a specific country. However, the more organized and structured the research ecosystem of a country, spanning across different levels, the wider the scope of the research management profession in that country, and vice versa.

In a context with a wide scope for research management, each level may shape the way research is managed on another level. For example, the existence of a strong national policymaking body for R\&I in a country would likely impact positively on the scope of national funding agencies. Such a body would provide the rationale for well-organized research management structures within universities in support of the researchers and research groups. But the reverse is also true: the role of RMAs in a university would be wider in scope and more holistic if a country had proper national structures and funding programs to promote, manage and fund research.

Therefore, in assessing the potential of the research management profession in small island states, one needs to gauge the levels at which the profession is exercised. Once these levels are determined, one must also assess: (a) the extent of their scope (the parameters), (b) their level and type of organization (public agencies, government departments, private companies), (c) the amount of resources (human, financial, space) available to them, and (d) the quality of such resources (qualified, experienced). Literature acknowledges that the organizational level is most commonly observed, particularly among universities. A systematic review conducted by Derrick and Nickson (2014) on the research management literature published between 2003 and 2013 shows that $70 \%$ of publications deal with a university context rather than any other research institution. Thus, in assessing the rationale for the research management profession in small island states, it is pertinent to analyse the university milieu in these states in some detail, as we do in the following section. 


\section{Universities in small island states}

\section{Feasibility in a globalized world}

Whereas it is probably unthinkable to question the presence of universities in large states, the feasibility of having a university in a small island state is not automatic. Universities in small island states often face constraints that limit the range of programs that they can offer and the research that such universities can engage in. This limitation contrasts with opportunities for universities in large countries to benefit from economies of scale and the ability to offer specialized services (Bray, 1992). In view of these limitations, some small island states may be unable to operate universities at all. As an alternative, such states might opt for regional solutions or develop strategic alliances with universities from larger, metropolitan countries or former colonial powers that will cater for their higher education needs. Without their own universities, small island states would have to send their students to study abroad, thus running the risk of brain drain in favour of larger and more resourceful countries. According to Christensen and Mertz (2010), the brain drain is inherent in small states, particularly in islands, since migrants might never return to their country of origin if the country of destination offers wider opportunities.

The absence of a university in various small island states makes such states dependent on regional institutions or foreign countries to address their higher education needs. Nevertheless, the existence of a university in such states does not eliminate the challenge of the brain drain. It could even be argued that the existence of a university in a small island state may promote emigration, as "individuals with higher levels of education are more likely to have a broad understanding of the world and of the opportunities in other countries" (Bray \& Packer, 1993, p. 35). Thus, in spite of having access to higher education training in their country of origin they may still decide to leave in search for more opportunities abroad.

In a more globally connected world, the notions of smallness and islandness have taken different dimensions. Interaction between countries, whether large or small, islands or mainlands, know no physical boundaries. Although geographical distance and physical location remain undisputed factors that characterize islands by their nature, globalization has contributed significantly towards the permeability of borders, whether imposed by land, sea or politics. This has enabled small island states to build virtual bridges and put in place collaborative efforts which, before the advent of globalization, were simply unthinkable. A number of authors consider Singapore an example of best practice in this regard (e.g., Armstrong, 1998; Briguglio, 2010; Mehmet \& Tahiroglu, 2002; Tan \& Olofinjana, 2005). In spite of the inherent characteristics associated with its island status and small geographical size, Singapore has managed to overcome several barriers through strong political will, building the right infrastructures and fostering strategic alliances with key partners. To this extent, Singapore is nowadays a case of contention in the literature because on one hand it is still considered to possess certain characteristics of a small island state (e.g. peripherality, high density, close personal relations); but, on the other hand, its pace of development has been significant, including a fivefold increase in population over the past 50 years (from below 1.5 million in the 1950s to over 5 million in 2016 (World Bank, 2016).

Globalization has therefore redefined several conditioning factors that were traditionally relevant to small island states. For example, the brain drain has often been considered detrimental to the country of emigration (Lucas, 1998), particularly for small states and peripheral regions that have historically faced a strong migratory-pull of graduates to core 
regions (Boucher, Conway \& Van Der Meer, 2003). However, as the methods of interaction and communication have evolved over time, migration may also lead to 'brain circulation' (e.g., Brock, 1988; Crossley \& Holmes, 2001; Kirkland, 2008; Poirine, 2014; Saxenian, 2005). This implies that migrants who leave their peripheral region or small state of origin have the possibility of building a wealth of knowledge that they can relay back to their home countries or regions through strategic alliances. Migrants from a small island state have the possibility to provide their country of origin with access to global networks and connections that would have otherwise been impossible to build and maintain.

\section{Conditions of survival}

Notwithstanding these contrasting views on the brain drain, the need for any state (large or small) to have universities that can provide social and political leadership is also a recognized fact (Bray, 1992), to the extent that universities exist in some of the smallest countries, whether islands or not (e.g. Andorra, Bhutan, Guyana, Samoa, San Marino, Seychelles and Solomon Islands). Small island states often have just one or a main, comprehensive, national publicly-funded university that provides a means of identity and national prestige, and which may be seen as an attractive beneficiary for potential donors and patronage (Lillis, 1993). Such a university is believed to be capable of responding with greater flexibility to the national development needs of the small island state, through the provision of more culturally-sensitive and needs-oriented higher education than might be possible to offer in larger countries with several universities, each with their own agendas (Teasdale, 1993),

In spite of this potential flexibility, national publicly funded universities in small island states are often characterized by a constant struggle to attain and maintain a degree of autonomy from political influence (Nkrumah-Young, Huisman \& Powell 2008) and several demands from stakeholders. The limited resources, absence of economies of scale and pressure towards economies of scope may hinder the range of services provided by universities in small island states. In the absence of a wide network of universities (publicly and/or privately funded), the single or the few universities that may exist in a small island state may face significant and diverse pressures to address as many needs and interests as possible. These universities have to address, among others, the teaching, research and outreach requirements of a small island state, in spite of being often faced with limited space, human and financial resources. According to Bray and Packer (1993) there is a limit to how far universities in small island states can cater to national demands. In practice, these demands may be addressed in a fragmented manner, possibly mutually exclusive of each other and largely as a direct function of available resources. For example, teaching is very often considered a necessary service that a university in a small island state cannot abandon. Hence, when faced with several resource constraints, research may be considered of secondary importance, or even non-existent. Under these conditions, the survival of the research management profession might be hanging by a thread.

\section{RMAs hanging by a thread}

As small island states struggle to justify the feasibility of their universities (if any), in the wake of globalization and with the constraints mentioned above, the research management profession in small island state universities faces a number of threats. First, in the absence of 
an effective research mission that includes programmed and collaborative university research (rather than just individual solitary research), there is probably no scope for having university RMAs, research policies and research support structures. Although this risk is a realistic one, it is probably less likely to have any major impact in those small island states where universities exist, because they probably still include research on their missions and agenda, for the reasons mentioned earlier.

Yet, the inclusion of research in the university agendas might actually pose a second and more significant threat to the research management profession. The limited resources and the over-arching priorities associated with teaching and outreach to society may heavily deplete the possibility of good quality research in small island state universities. A sufficient level of critical mass is an essential pre-requisite for achieving quality and specialization (Cooke \& Leydesdorff, 2006). However, critical mass requires small island states to identify areas of comparative advantage and to devote the necessary resources to attract and maintain the best brains in the selected priority areas. This specialization and selectivity needs to be accompanied by favourable working and living conditions, competitive salaries, access to advanced research infrastructures, international networks and sustainability of funding. In the absence of sufficient resources to achieve this critical mass, the role of RMAs in a small island state may be hard to exercise and likely to be characterized by huge and relentless efforts to move unmoveable mountains.

Third, selectivity might be impossible in a small island state university. By being selective, certain services or disciplines that are not catered for by the university might not be catered at all in the small island state. Selectivity is often not very well met, not only by researchers or academics, who might consider it compromising to their already restricted careers, but also by politicians. The latter may rather prefer to keep as many people happy as possible for the sake of not losing electoral votes rather than taking certain decisions that will ultimately result into making better use of limited resources.

In this rather difficult context, the research management profession may have a restricted purpose in small island state universities, in view of limited resources and the need to preserve academic freedom. Yet, these limiting factors may provide RMAs in small island state universities with opportunities to be more creative, outward-looking and critical in their policies and strategies. Thus, in allocating limited research funds among various researchers, research groups or research disciplines, RMAs may opt for a bottom-up approach instead of adopting top-down strategies based on selectivity. This can be achieved by adopting an evaluation system that measures, as objectively as possible, the research efforts and the outcomes of university research within a competitive funding mechanism. In this way, RMAs would justify the allocation of limited resources towards the most promising and successful researchers or research groups. The inherent problem of limited resources can be turned into an opportunity to make the best possible use of resources without imposing an agenda.

\section{Professional associations in small island states}

Another aspect in the discussion about the rationale for the research management profession in small island states relates to the affiliation of RMAs, universities and other research entities to professional research management associations. The profession is represented by various international associations of research managers and administrators, including NCURA, SRAI, EARMA, UK ARMA, and the International Network of Research Management Societies (INORMS). Although members in these associations represent various types of research 


\section{The research management profession within universities in small island states}

organizations, the majority of their memberships tend to derive from universities. Moreover, most of these associations also provide academic recognition in research management that spans from under-graduate, to graduate and post-graduate degrees. Therefore, the affiliation to a professional association gives a sense of belonging to the RMAs with the profession at large. Such affiliation also increases the possibilities for RMAs to learn from best practices, to align their knowledge to that promoted by the profession and to keep up to date with the profession's pace of development.

In addition to the membership in international professional associations, some countries have also developed their own professional associations. While this is probably not surprising for the UK, the US or Australia, it is probably a positive revelation that one of the smallest of island states (in terms of population), Iceland, has its own professional association, IceARMA. Although this association is affiliated with and follows largely the direction given by the other international associations and those established in larger countries, it gives a sense of identity to its members as well as fosters co-operation with RMAs in other countries. The crucial point here is that the rationale for the research management profession is boosted significantly if such small island states take the plunge and start taking active roles in the profession even within their own national boundaries. In this way, the small island states can contribute actively and foster the profession, rather than just follow what other larger states promote.

The discussion on the rationale of the research management profession in small island states has shed light on the conditions that are required for legitimizing the profession in such contexts. It also highlighted circumstances that may boost the rationale for the profession and therefore provide a basis for pursuing affiliation. In the light of these circumstances and the natural barriers threatening the survival of the profession, the manner in which the roles of university RMAs may potentially be re-shaped and influenced by their small island state context shall be discussed next.

\section{Re-shaping research managers and administrators in small island state universities}

Perhaps, the best way to reflect on the ways in which the roles of RMAs are re-shaped in small island state universities is by referring to the four fundamental principles of the research management profession. The first principle compares RMAs to the oil in a complex mechanism. Their core work consists of reducing friction and keeping the process moving smoothly (Eurich, 1967). The second principle was articulated by Beasley (1970), who argued that RMAs should serve as mediators-expeditors of the grants process. As a third principle, Woodrow (1978) portrayed RMAs as facilitators of research; while, as a fourth principle, Rodman and Dingerson (1979) highlighted the need that RMAs must enjoy the trust of the researchers that they serve. While these principles are wide-reaching to all RMAs, irrespective of the size and type of context in which they are operating, their application and relevance to the context of a small island state university and small jurisdictions can be quite unique. This means that the role of RMAs in small island state universities cannot be analysed simply with reference to a standard job description that has probably been moulded upon the role of RMAs across a range of larger, more comprehensive countries. Rather, one has to understand how the university RMAs in a small island state adapt to the idiosyncratic characteristics and how their roles are tailored to address the specific research needs of the university and (in most cases) also of the country. Factors that re-shape the roles of RMAs in small island states are discussed in turn below. 


\section{Strong social cohesion, closely-knit societies and conflict management}

Literature shows that small island states have a social ecology of their own (Baldacchino \& Farrugia, 2002). This often leads to the creation of closely-knit societies and personalized relationships with strong social cohesion among small communities. People in small island states often have to learn to live in a face-to-face society with back-to-back relations (Baldacchino, 1997), since they are in regular contact with each other. These close relations may impact positively and negatively on the ways in which university research is managed. From one end, such relationships may be considered as an asset, particularly when negotiating in conflict situations, mediating, lobbying and fast tracking processes to meet certain deadlines. But from the other end, the personalized style of management and the close relations it may find hard to avoid may lead to potential problems, also because of public perceptions of coziness and familiarity which, in small island states, can be easily and quickly transmitted from one person to another. Moreover, potential rivalries within a small island state university may lead to duplication of efforts and costs, time wastage and inefficient use of other limited resources. Rivalries may arise among research groups, departments, faculties and also between individual academics/researchers and administrators. They may take the form of competition as to whose voice gets heard, hostility towards one another and possibly a preference to collaborate with external partners in order to avoid the hassles of seemingly inevitable tetchiness in dealing with fellow colleagues. These occurrences can in turn jeopardize the RMAs' ability to expedite the grants process, to facilitate the research and to build the trust of those they serve. RMAs may have to constantly seek alternative ways to, either try and bring distant parties together or else to steer away from the mainstream structures in order to manoeuvre around the hurdles and avoid clashes from happening.

Moreover, once social unity is distorted, it may be impossible to restore. According to Farrugia (2002, p. 17) "in communities where practically everyone knows everyone else, individuals' utterances and actions soon become public knowledge...[and] it is extremely difficult to avoid the polarization that ensues". The closer the people are to each other and the more frequent they interact, the greater is the possibility that friction arises. Thus the role of RMAs in a small island state university may become heavily characterized by conflict management and resolution. This may happen at the expense of other, more strategic and long term roles of RMAs, including the setting up of research support services and the building of trust with academics and researchers.

\section{Multi-functionalism and specialization}

Another aspect that re-shapes the role of RMAs in small island state universities is that pertaining to the concept of specialized professionals. Bray (1991) argues that professionals in small island states need to adapt their knowledge to peculiar conditions, such that their specialization is more likely to involve breadth rather than depth. This breadth specialization arises because the limited human talent as well as the limited resources, including funding, that often prevails in small island states, may restrain professionals from specializing in one particular area. Instead, it is more likely that professionals in a small island state are multifunctional (Farrugia \& Attard, 1989) and responsible for several aspects of the job, which in larger countries would probably be segregated among a number of professionals. University RMAs are not exempt from these characteristics.

In one way, multi-functionality can be beneficial for university RMAs since they are more likely to be involved in each and every aspect of any particular situation, thus having a 


\section{The research management profession within universities in small island states}

broader and a more wide-ranging view of the job. But from the other end, the multiplicity of roles may have negative effects on the university RMAs as they may be unable to develop the necessary level of specialization required to support researchers properly and holistically. For example, in a small state university, there might be a general-purpose lawyer who deals with all research-related matters. But such a lawyer might not have the necessary expertise, specialization and time to deal proactively with more technical matters, such as Intellectual Property Rights (IPR) and patents. Mundane, ad hoc chores that require immediate attention are more likely to take precedence over more strategic, thought-provoking matters that might be required from university RMAs. Farrugia (2002) argues that the situation becomes even more frustrating when foreigners are called in to deal with certain matters that could have easily been handled by local RMAs but which was not possible due to limited time and resources at hand. These situations and the multi-tasking responsibilities may lead to a physical and mental drain on the RMAs who may not be able to shift rapidly from one task to the other or from one decision-making situation to another, thus undermining their roles and capabilities (Baldacchino \& Farrugia, 2002).

\section{Skills and functions of RMAs}

The constraints imposed by smallness tend also to impinge on the function of RMAs. Since the early days of the research management profession, the function of RMAs has been a point of contention especially within universities. First of all, a standard professional profile of an RMA has been lacking, in view of the continuously evolving roles and the wide diversity of tasks undertaken by RMAs (Trindade \& Agostinho, 2014). Secondly, the level of academic qualifications for RMAs has often been a point of contention. Shelley (2010) argues that the more RMAs possess characteristics that are similar to those of academics/researchers, such as holding doctorate degrees, publishing in peer-reviewed journals and having experience in research funding, the more the research management profession gets closer to the academic field. However, the closer these two fields become, the greater is the impossibility to develop a clear profile for RMAs that distinguishes them specifically from other academic fields.

A third contention on the function of RMAs is that there is no single point of entry into the profession. Various authors recognize that RMAs require a range of specialist skills, such as budgeting, negotiation, commercialization, IPRs, communication and management (Connell, 2004; Green \& Langley, 2009; Landen \& McAllister, 2006; Tauginiené, 2009). An RMA may have to simultaneously master the roles of manager, lawyer, financier and quasiresearcher, while rendering assistance to faculties in carrying out research and representing university needs and strategic priorities. With all these skill requirements, RMAs may get involved in the research management profession as a result of their academic qualifications in other professions, such as accountancy, law, management, business studies and/or public administration. This 'transfer' from other professions to the research management profession is also exacerbated because, until now, there are no academic courses that specialize on the formation of RMAs right from the beginning. Qualifications in research management presently require the student to be somewhat already involved in the profession, by working within a research-oriented entity, maybe through indirect roles, such as those of lawyers, accountants and managers or through direct roles, such as project support officers and project support managers, but without any recognized qualification in research management. This has been the cause of misconceptions faced by RMAs because, as opposed to other professions, 
they first 'join' the profession through employment and then they obtain the recognized qualifications in research management.

This peculiar way of joining the profession may potentially re-shape the role of RMAs in small island state universities in two ways. First, small island state universities may not have the luxury to employ a large number of professionals that can specialize in different aspects of their discipline. Therefore, it is more probable that the research management function of a university 'borrows' the skills of the limited professionals to address its research support needs. Besides exacerbating the concept of multi-functionalism and limiting the potential for specialization, as discussed in the previous sections, this practice may create confusion about the real function of RMAs. At one instance, their role may be perceived to be that of a lawyer or an accountant dealing with general university business. At other instances, their role may be perceived as one that supports research and possibly even directing it. Academics and researchers who strive to obtain support for their research within universities in small island states might be frustrated by the lack of clarity in the roles and may perceive a lack of commitment by the university towards supporting and encouraging research. This situation may be aggravated because the needs of researchers in small island states are very often not correlated to the availability of resources. It is likely that researchers in small island states would still expect the level of support and expertise that they would have probably expected in a university in a larger state. Consequently, university RMAs in small island states end up facing demands similar to those of larger, more resourceful universities, but with the limited tools that a small island state university can provide. This limitation can create an incongruity between RMAs and researchers that will persist unless both sides understand the limitations imposed by the small island state context.

Second, the lack of a clear career route for RMAs may potentially lead to significant fragmentation in the provision of research support services in small island state universities. This may happen because different people working in different departments may be required to provide their services piecemeal, to the detriment of the researchers who may have to resort to different persons in order to submit a proposal for a research grant or to implement a research project. This may also potentially cause distrust between the RMAs and the researchers as the latter may not be convinced about the level of specialization and relevance in the service they receive from RMAs. This will eventually defeat one of the fundamental principles of research management: to build trust. Consequently, this may also impact negatively on other fundamental principles.

\section{Scope of the RMA work}

The discussion on the re-shaping of the profession in a small island state university would not be complete unless one examines the scope of the RMA work. Such examination needs to assess whether the characteristics of a small island state university impact on the range of services provided by RMAs and the structures of research management offices. In the same way that one cannot transfer the literature about larger states onto small island states blindly, one cannot uncritically transfer what is known about the scope of RMA work in larger countries onto the scope of RMA work in small island states. We revisit the literature and reflect on the two aspects that influence the breadth and depth of research management within a university.

First, research management in universities (irrespective of their size) may be exercised in different stages. The most common ones are the pre-award stage and the post-award stage. 


\section{The research management profession within universities in small island states}

The pre-award stage is the proposal phase of a research project that deals with searching for funding opportunities and assistance in proposal development and budgeting, among others. The post-award stage is concerned with project implementation, financial management, reporting, project deliverables and auditing, among others. To these two sequential stages, one may also add other phases that do not necessarily follow in a linear process. For example, strategy is often considered to fall within the scope of the RMA work all along the research process, starting well before pre-award and continuing after the post-award phases. Commercialization of intellectual property, public engagement and the dissemination of research results are also often part of the research process that do not occur necessarily in a linear fashion.

The second aspect that falls within the scope of university research management relates to hierarchical levels. There are two main hierarchical levels within a university (Chun, 2010; Connell, 2004; Shelley, 2010, Temples, Simons \& Atkinson, 2012). Research management at a departmental level is conducted at the level of faculties, institutes or research centres and is more concerned with "providing information, helping with the mechanisms of research fund bidding and other more generic roles" (Shelley, 2010, p. 47). Research management at the central level tends to have "a wider focus on the implementation of institutional research policy decisions, national or international-related contracted research work or hold specific research expertise" (ibid.). The allocation of resources among these two levels varies from one university to the other, to the extent that some universities may have one level only, although the existence of departmental research management is often accompanied by some form of central direction. The extent of support by a university on these two levels depends heavily on the availability of resources. Whereas departmental support is usually highly sought by academics and researchers, it generally requires a large investment in human resources, something that may be problematic when resources available for research management are heavily restricted. Similarly, providing centralized support may also put heavy demands on university funds because it requires a team of people to cater for the needs of the entire university researcher population; even though this is probably a cost-effective option rather than a decentralized one.

The distinction between the stages in research management and the levels at which research may be managed and supported is important from the perspective of small island state universities because it sheds light on the scope of the RMA work and how it may be reshaped. While support throughout all the stages of a research project at both departmental and central levels is desirable and potentially beneficial to small island state universities, the limited resources available to such universities may pose significant constraints on the level of support that may be provided. Limited human and financial resources are likely to lead to multi-functionalism and limited possibilities for in-depth specialization. Therefore, small island state universities may face significant restrictions in their ability to support research at all of these levels and stages. These restrictions make the job of RMAs a challenging one because any likely demand for support at these levels and stages would be impossible to satisfy. This may breed dissent and mistrust from researchers and academics who may consider research management as failing to address their needs.

Moreover, the demand for adequate research management structures may become quite pressing in small island state universities because the limited funding for research from local sources, tends, very often, to oblige researchers to look for external sources of funding (for example, through European Union funds). While opening a world of opportunities for 
researchers, external funding is very often highly competitive and comes with several strings attached, including regulatory and compliance requirements, strict deadlines, bureaucratic processes and possibly an element of co-financing. While these strings widen the scope for RMA work and the rationale for having specialized people within a university to support and manage the research, they may exacerbate the problem of restricted resources in small island state universities. On the one hand, external funding may offer the only or the most important possibility for small island states to obtain funds for research. But on the other hand, it may also be the source of further restrictions, as universities may be unable to cope with the demands brought about by the external sources of funding. This may lead to possible ineligibility or suspension of funds if there are insufficient structures and resources to ensure accountability. In addition, universities in small island states may end up unable to set forth or to implement their own strategies, since the external sources of funding may significantly influence their own agendas. RMAs may therefore become key resources in bridging the gap between the agendas of universities in small island states and those of external funding agencies. This bridging would enable researchers in small island state universities to engage in larger scale collaborative research which would otherwise not be possible without the external funds and without the support of RMAs acting as facilitators of research.

\section{Conclusion}

The existence, redefinition and the flourishing of the research management profession in small island state universities depends on a variety of factors, taking into consideration the specific context and circumstances.

First, the extent to which the profession can be widely diffused in a small island state depends on the existence of the different levels in which it can be exercised. The wider the research landscape of a small island state and the more articulated the various levels are, the broader is the scope for the research management profession. To this, one must add the wider dimension in the way things are managed nowadays in a globalized world, such that no matter how small a country is, it is an integral part of a globalized inter-connected world in which the actions on one level may affect several levels in multiple countries quite rapidly.

Second, the profession can flourish within small island states only if at least a homegrown university exists: something that cannot be assumed in small island states, given that particular circumstances, history and socio-economic context may make it impossible or disadvantageous to set up a university in such a state.

Third, the existence of at least one university in a small island state provides a rationale for the research management profession and for the roles of university RMAs. However, the profession may possibly be faced with several restrictions due to size, insularity and limited resources of a small island state. These restrictions may lead to a brain drain and to limits to the possibilities for specialization and the development of critical mass, thus conditioning the role of RMAs and possibly preventing these from pursuing a path towards in-depth specialization.

A fourth implication is that RMAs need to be creative enough to come up with solutions that take into consideration the limitations faced by the small island state context. It can be argued that RMAs in a small island state are masters (or mistresses) of their own destiny, because the extent to which they are able to cope with the various challenges depends on their ability to understand the small island context and to be creative and open to paths that may not be required to university RMAs in larger countries. For example, they may have to 


\section{The research management profession within universities in small island states}

have a very clear understanding of the way relations work in small communities and be ready to focus more on conflict resolution in order to reduce friction and to keep the ball rolling. They may have to be multi-functional and work under stressful conditions in order to address the wide needs of university researchers in the absence of sufficient resources. They may have to sacrifice their specialization to a more generic role, yet being able to get a wider understanding of the context while their services may be more wide-reaching. This stance may eventually build trust and significant relationships between researchers and RMAs in the long term: RMAs may be involved in many of the milestones in a researcher's career in a small island state university.

A fifth factor that influences research management in a small island state context is the existence or otherwise of a professional association of research managers and administrators within their own country. To our knowledge, the only small island state that has set up such an association so far is Iceland. The existence of such association depends on the size of the research landscape, including the existence of more than one university - Iceland has seven - a network of research organizations and a strong culture in favour of research and its management. Although these factors may not all exist in small island states to justify a professional association of RMAs, they offer scope for the RMAs in small island state universities to affiliate themselves with other international professional associations of RMAs. This affiliation gives a sense of belonging to the RMAs within the profession, and widens its scope, offering opportunities for professional development, lifelong learning and qualifications in research management proper. It also portrays a better image of RMAs to the researchers and to the society to which they belong.

Finally, when it comes to university structures in support of research, RMAs in a small island state university need to find that elusive right balance with the limited resources at hand. RMAs have an important role in the extent to which universities in small island states follow the agenda set by others, including funders. RMAs also need to offer as many opportunities to researchers as possible, including those deriving from external funding sources and from the teaming of researchers in larger scale collaborative projects. Moreover, RMAs need to reach a compromise between being closer to the researchers at a departmental level and having strong central structures that give a strategic direction to make the best possible use of limited resources.

This paper asked whether the research management profession can operate properly within small island states; and suggested that there is benefit in pursuing research that investigates specifically the research management profession within small island state contexts. We conclude that the RMA faces a tough job in a small island state university. However, with the right conditions, the profession can survive and prove its effectiveness. These in turn depend on the ability of the members of this young profession to be redefined and to accommodate the idiosyncratic characteristics of small island states. The characteristics of small islands and their universities, where these exist, have the potential to develop a unique RMA profile and to expose aspects of the profession that are less applicable within larger contexts. This uniqueness in the profile of an RMA creates scope for further studies to explore similarities and differences in the role of RMAs between different contexts and under different circumstances. 


\section{References}

Armstrong, H.W. (1998). A comparison of the economic performance of different microstates, and between micro-states and larger countries. World Development, 26(4), 639656.

Armstrong, H. W., \& Read, R. (2003). The determinants of economic growth in small states. The Round Table, 368, 99-124.

Baladacchino, G. (1997). Global tourism and informal labour relations: The small scale syndrome at work. London: Mansell.

Baldacchino, G. (2004). The coming of age of island studies. Tijdschrift Voor Economische En Sociale Geografie, 95(3), 272-283.

Baldacchino, G. (2005). Editorial: Islands: objects of representation. Geografiska Annaler: Series B, Human Geography, 87(4), 247-251.

Baldacchino, G. (2007). Introducing a world of islands. In G. Baldacchino (Ed.), A world of islands: An island studies reader (pp. 1-29). Charlottetown, Canada and Luqa, Malta: University of Prince Edward Island, Institute of Island Studies and Agenda Academic.

Baldacchino, G. (2013). Global tourism and informal labour relations: the small scale syndrome at work. Routledge.

Baldacchino, G., \& Farrugia, C. (2002). Educational planning and management in small states: Concepts and experiences. London: Commonwealth Secretariat.

Beasley, K. L. (1970). The research administrator as mediator-expeditor. Journal of the Society of Research Administrators, 2(1), 1-4.

Beasley, K. L. (2006). The history of research administration. In E. C. Kulakowski, \& L. U. Chronister (Eds.), Research administration and management (pp. 9-29). Sudbury, MA: Jones and Bartlett Publishers.

Boucher, G., Conway, C., \& Van Der Meer, E. (2003). Tiers of engagement by universities in their region's development. Regional Studies, 37(9), 887-897.

Bray, M. (1991). Ministries of education in small states: Case studies of organization and management. London: Commonwealth Secretariat.

Bray, M. (1992). Educational planning in small countries. Paris, France: UNESCO.

Bray, M., \& Packer, S. (1993). Education in small states: Concepts, challenges and strategies. Oxford: Pergamon Press.

Briguglio, L. (2010). Small states and economic resilience: Lessons for larger developing countries. Occasional Paper No. 5. Msida, Malta: Occasional Paper, Islands and Small States Institute, University of Malta.

Brock, C. (1988). Beyond the fringe? Small states and the provision of education. Comparative Education, 24(2), 167-179.

Bushaway, R. (2007). Managing research (2nd ed.). Milton Keynes: Open University Press.

Christensen, A. E., \& Mertz, O. (2010). Researching pacific island livelihoods: mobility, natural resource management and nissology. Asia Pacific Viewpoint, 51(3), 278-287

Chun, M. B. J. (2010). Building a research administration infrastructure at the department level. Journal of Research Administration, 41(3), 77-84.

Connell, H. M. (2004). University research management: Meeting the institutional challenge. Paris, France: Organization for Economic Cooperation and Development.

Cooke, P., \& Leydesdorff, L. (2006). Regional development in the knowledge-based economy: the construction of advantage. Journal of Technology Transfer, 31(1), 5-15. 
Crossley, M. (2008). The advancement of educational research in small states. Comparative Education, 44(2), 247-254.

Crossley, M., \& Holmes, K. (2001). Challenges for educational research: international development, partnerships and capacity building in small states. Oxford Review of Education, 27(3), 395-409.

Derrick, G., \& Nickson, A. M. (2014). Invisible intermediaries: a systematic review into the role of research management in university and institutional research processes. Journal of Research Administration, 45(2).

Eurich, A. (1967). Reflections on university research administration. In S. Strickland (Ed.), Sponsored research in American universities and colleges (pp. 1-6). Washington DC: ACE.

Farrugia, C. J., \& Attard, P. A. (1989). The multi-functional administrator: Educational development in the small states of the Commonwealth. London: Commonwealth Secretariat.

Farrugia, C., J. (2002). Rewards and tribulations of senior education managers in small states. In G. Baldacchino, \& C.J. Farrugia (Eds.), Educational planning and management in small states: Concepts and experiences (pp. 13-24). London: Commonwealth Secretariat.

Gabriele, E. F., \& Caines, V. V. (2014). Leader being: Critical reflections on context, character, and challenge in the culture of research and its administration. Research Management Review, 20(1), 1-38.

Green, J., \& Langley, D. (2009). Professionalizing research management. United Kingdom: Higher Education Funding Council for England (HEFCE) and the Medical Research Council (MRC).

Hansen, S., \& Moreland, K. (2004). The Janus face of research administration. Research Management Review, 14(1), 43-53.

Hay, P. (2006). A phenomenology of islands. Island Studies Journal, 1(1), 19-42.

Katsapis, C. C. (2012). The incidence and types of occupational role stress among university research administrators. Research Management Review, 19(1), 1-23.

King, R. (2009). Geography, islands and migration in an era of global mobility. Island Studies Journal, 4(1), 53-84.

Kirkland, J. (2005). Towards an integrated approach: University research management in an institutional context. International Journal of Technology Management \& Sustainable Development, 4(3), 155-166.

Kirkland, J. (2008). Brain drain, brain gain and brain circulation: migration in the 21st century. The Association of Commonwealth Universities Bulletin, 164(6), 20-22.

Landen, M., \& McAllister, M. (2006). The research administrator as a professional: Training and development. In E. C. Kulakowski, \& L. U. Chronister (Eds.), Research administration and management (pp. 75-82). Sudbury ON: Jones \& Bartlett Learning.

Lillis, K. M. (Ed.). (1993). Policy, planning and management of education in small states. Paris: UNESCO, International Institute for Educational Planning.

Lucas Jr, R. E. (1998). On the mechanics of economic development. In D. P. Jacobs, E. Kalai \& M. I. Kamien (Eds.), Frontiers of research in economic theory. The Nancy L. Schwartz memorial lectures, 1983-1997 (pp. 61-70). Cambridge: Cambridge University Press. 
McCall, G. (1994). Nissology: the study of islands. Journal of the Pacific Society, 17(2-3), 114.

Mehmet, O., \& Tahiroglu, M. (2002). Growth and equity in microstates: does size matter in development?. International Journal of Social Economics, 29(1/2), 152-162

Moncada, S., Camilleri, M., Formosa, S., \& Galea, R. (2009). Islands at the periphery: Integrating the challenges of island sustainability into European policy. Msida, Malta: Islands and Small States Institute, University of Malta.

Newitt, M. D. D. (1992). Introduction. In H.M. Hintjens \& M.D.D. Newitt (Eds.), The political economy of small tropical islands (pp. 1-17). Exeter: University of Exeter Press.

Nkrumah-Young, K. K., Huisman, J., \& Powell, P. (2008). The impact of funding policies on higher education in Jamaica. Comparative Education, 44(2), 215-227.

Poirine, B. (2014). The significance of geographic location in island studies: A rejoinder. Island Studies Journal, 9(2), 373-376.

Rodman, J. A., \& Dingerson, M. R. (1979). What is a university research administrator current and future? Journal of the Society of Research Administrators, 11(2), 5-11.

Saxenian, A. (2005). From brain drain to brain circulation: Transnational communities and regional upgrading in India and China. Studies in Comparative International Development, 40(2), 35-61.

Shambrook, J., \& Roberts, T. J. (2011). 2010 profile of a research administrator. Research Management Review, 18(1)

Schuetzenmeister, F. (2010). University research management: An exploratory literature review. Berkeley CA: University of California, Institute of European Studies.

Shelley, L. (2010). Research managers uncovered: Changing roles and 'shifting arenas' in the academy. Higher Education Quarterly, 64(1), 41-64.

Sultana, R. G. (2006). Challenges for career guidance in small states. Msida, Malta: EMCER.

Tan, K. S., \& Olofinjana, A. O. (2005). Impact of research and experimental development in science and technology on small developing states. Brunei: Faculty of Science, Universiti Brunei Darussalam.

Tauginienè, L. (2009). The roles of a research administrator at a university. Viesoji Politika Ir Administravimas, 30(1), 45-56.

Teasdale, R. (1993). Higher education in small systems: A pacific island perspective. In K. M. Lillis (Ed.), Policy, planning and management of education in small states (pp. 126150). Paris, France: UNESCO, International Institute for Educational Planning.

Temples, B., Simons, P., \& Atkinson, T. N. (2012). Research administration training and compliance at the department level for a predominantly undergraduate institution. Research Management Review, 19(1), 42-60.

Thorhallsson, B. (2006). The size of states in the European Union: theoretical and conceptual perspectives. European Integration, 28(1), 7-31.

Trindade, M., \& Agostinho, M. (2014). Research management in Portugal: a quest for professional identity. Research Management Review, 20(1), 1-8.

Woodrow, R. J. (1978). Management for research in US universities. Washington DC: National Association of College and University Business Officers.

World Bank (2016). Total Population Statistics for Singapore. Retrieved from http://data.worldbank.org/country/singapore 